\title{
Household Characteristics and Food Security in Low-Income Urban Areas of South Africa
}

\author{
Mandisa Putuma MOKWENA ${ }^{1}$ \\ Paul-Francois MUZINDUTSI 2
}

DOI: $10.24818 / \mathrm{mer} / 2021.12-08$

\begin{abstract}
In South Africa, food security at the household level is an issue still needing empirical attention. This study conducts an empirical analysis on the effect of household size, income of household head, gender of household head, location of the household, and distance from food markets on food security in the Gauteng Province of South Africa. A binary logistic regression model is estimated to analyze determinants of food security from 900 households randomly selected from three townships of Gauteng Province, South Africa. Data was collected using a survey questionnaire, with food security measured by the Household Food Insecurity Access Scale. This study shows that the income of the household head promotes food security while household size and location of the household contribute to food insecurity. Our results also show that the gender of the household head is essential in maintaining sustainable levels of food security. Furthermore, it was found that the distance from food markets neither makes households food secure nor insecure. This study validates that matriarchal households exhibited comparatively greater food security than male-headed households. The findings of this study are essential in formulating policy on food security in low-income areas.
\end{abstract}

KEYWORDS: food insecurity, urban food security, household, food accessibly

JEL CLASSIFICATION: $D 13,130$

\section{INTRODUCTION}

Food Security is the key index of the degree to which a basic households food needs are met. There are various internationally respected ways of quantifying food security as it presents at different levels, aimed at satisfying basic economic needs and health requirements (Oriola, 2009). To achieve this, agricultural production, as the source, needs to be augmented with a working knowledge of climatic and seasonal conditions, its inter relatedness with the environment and the global changes, types of organic and chemical fertilization, judicious use of insecticides and pesticides, crop treatment (Oriola, 2009). Coupled to this is an acute awareness of market prices, their fluctuations and the operational and mechanisms that dictate market forces. The principal objective of food security is for individuals to perpetually obtain adequate food for survival and sustenance. The food security of a country is a measured by the strength or weakness of the agricultural sector which is further conditioned by factors including: drought, political instability, inconsistent agricultural policies, inadequate storage facilities, inaccessibility to credit, and inadequate market mechanisms for agricultural products. An FAO Report of 2008 stated that is further extenuated by a high unemployment

\footnotetext{
${ }^{1}$ Independent Researcher, South Africa, mandisa.mokwena@gmail.com

${ }^{2}$ University of Kwa-Zulu Natal, South Africa, MuzindutsiP@ukzn.ac.za (Corresponding Author).
} 
rate, an inadequate social welfare system, and a high HIV/AIDS infection promulgates even further food insecurity.

Limited economic access to food not only in monetary terms but also in terms of access to land, credit facilities, and good health facilities, all of which affect the food security status at the aggregate level (Omonona \& Adetokunbo, 2007). Idachaba (2004) notes that a shortage in food supply occurs when the population growth rate is at a higher growth index rate than that of food production. This often leads to rising prices of food items which further have reduces access to adequate food, especially in the rural areas. Moreover, inflationary pressures in food exporting countries have sparked off domestic inflation, making food increasingly inaccessible to vulnerable groups (Munir \& Esteban, 2011).

In the case of South Africa, food availability is not a serious challenge since the country is a net exporter in terms of food production; however, food accessibility and food utilization are of major concern since majority of the households are unemployed and have no alternative means of generating income (Grobler, 2015). According to a study by the Integrated Food Security Phase Classification (IPC, 2021) 9.34 million people in South Africa from September to December 2020 faced high levels of acute food insecurity, with the Gauteng Province noted to have one of the highest levels of food insecurity. The study revealed that 11 percent of the population in Gauteng, find themselves in a severe status of food insecurity. As the most populated province in South Africa, suffering from high food insecurity levels, further research on food insecurity in Gauteng, and its drivers thereof, is of significant importance for the future development of the province.

The food utilisation challenges are due to lack of required skills in transforming available foods to the most efficient use for healthy life. Thus, the food accessibility from an affordability viewpoint and utilisation challenges are the centre piece of this study, consequently the study raises the following research questions: What is the influence of food accessibility from an affordability viewpoint on household food security in the townships of Gauteng Province? Does food utilisation have an impact in the townships of Gauteng Province at the household level? Thus, this study intends to analyse the level household food security and ascertain the key determinants of household food security in the Gauteng Province. In achieving these research objectives, this study is guided by the theoretical and empirical underpinnings on food security in South Africa, where the focus is primarily on the demand side of food security since the supply side is not a major challenge in the South African context.

\section{LITERATURE REVIEW}

\subsection{Conceptualisation and determinants of food security}

Food security is a multi-dimensional phenomenon with various conceptualisations. In the mid-1990s, there were more than 200 different definitions, whilst the debate on food security had was explored greatly in the 70s (Maxwell, 1996). Food security as a concept emerged during the global food crises focusing principally on the supply aspect of food availability at both national and international levels. This food security definition has evolved greatly from its earlier narrow focus as it became apparent that the success of the green revolution did not necessarily lead to an improvement in food insecurity and malnutrition for everyone. This led to the Food and Agriculture Organization (FAO) reappraising its understanding of broadening terminology on food security with the inclusion of both economic and physical considerations (FAO, 1996:1). It was then defined as: "when all people at all times have physical and economic access to sufficient, safe and nutritious food to meet their dietary needs and food 
preferences for an active and healthy life" (FAO, 1996:1). This new approach put the emphasis not only on supply side but also on the demand side, consumption and on the access to food both physically and economically. The FAO (2006) further redefined the concept to include social access to food and the resultant deduction was the identification of further dimensions as highlighted in its document released in 2001. These have been deduced from the conceptualisations by FAO over the years, namely, food availability, accessibility, utilization, and stability. Though, the food stability dimension overlapped in both the food availability and accessibility dimensions which serve as feedback to food security policies.

Food security can be viewed from the point of access, availability, and food utilization (FAO, 1996). Food availability promotes food production by household for sustenance. Bonuedi et al., (2020) contend that food availability can exist at household and national levels. Food can be accessed in various forms including through household production, commercially imported, or exploring the possibility of identifying other forms of food assistance (USDA, 2006). In the work of Sen (1981), the emphasis shifted from limited availability to inadequate access, where inadequate access was defined as the purchasing power to access food. Thus, in order for food security to be attained, food must be available in sufficient quantities and be of appropriate quality but purchasing power must exist to obtain or access food in sufficient quantities.

Food accessibility is therefore attained when all individuals in a household have adequate resources and entitlements to appropriate food for a safe and nutritious daily diet. The food may be accessed from markets or even as transfers of gifts or grants. Access to food further depends on the income availability of the household, its distribution across the household, and the prices of food (USDA, 2009). For a household to have access to food, they should have adequate entitlements to acquire adequate food for the household. Entitlements can be defined as a guarantee to access a benefit based on legislation and rights (FAO, 2006). It should, however, be noted that access to income or entitlements does not equate to food security. For example, two households with the same composition and entitlements may differ in terms of food security depending on which foodstuffs they buy and the distribution of the income that is expended on food. Households should also be able to acquire the food they prefer in a socially acceptable manner.

In addition to food accessibility, there should also be means to enable sufficient food utilisation. Food utilization refers to the household or individual's eventual use of the food once it has been obtained. According to the FAO (2006), practices that fall in the category include preservation, storage, selection, preparation, and final consumption of the food. For adequate absorption of nutrients, food must be selected, stored, prepared, distributed, and eaten in a proper way (Devereux \& Maxwell, 2003). According to the FAO (2006), food utilization is concerned with adequate nutritional absorption, good nutritional outcomes, and nutritional security. It is influenced by availability of safe water, sanitation, nutrition and health education, and health care services. USDA (2006) notes that food utilization depends on the knowledge on food storage and processing (preparation) techniques as well as the basic principles of nutritional proper care and illness management. In developing countries where there is poor sanitation, limited access to clean water, and poor storage facilities, there are high incidences of diseases; hence food utilization is hindered. To maximize food utilization especially in developing countries, there should be investment in nutrition education, health care, and sanitation (Boadiet al., 2005) to ensure food stability. 
On the other hand, food stability relates to a consistent maintenance of food security over a reasonable period of time of both the ability and the access to food. Food accessibility and/or availability should not be lost due to economic or climatic shocks such as floods or drought, sudden political conflicts or war, and high food prices or price hikes. According to Dreze and Sen (1989), food stability involves entitlement promotion and protection. Promotion involves helping people to ensure long term entitlement to food while protection refers to the provision of safety nets that protect against shocks. Stability is therefore ensured when shocks that may hinder food security are effectively managed once they arise. Several community conditions impact on food security, these are either considered as immediate whilst others are considered underlying community fundamentals (Alemu, 2005). The prevalent conditions impacting on agricultural conditions are normally poor infrastructure, poor road network, poor connection especially for rural households. Underlying community conditions are conditions endemic in particular communities that creates further divide in its ability to access markets. The technology also has been the new dividing trend for vulnerable communities preventing them from accessing markets, which include the food market.

Community status could be further adversely impacted by inclement local and international market conditions based on poor policy designs. These factors could inhibit access for poor communities especially cases of ill-health of its people due to health outbreaks such as HIV, Ebola, COVID-19. Diseases and health pose a serious threat to sustainability of communities when it targets the economically productive group. Recently, Guina et al., (2021) argue that the COVID-19 global pandemic has negative implications for food security in sub-Saharan Africa. They demonstrate that COVID-19 has disturbed the food supply chain in terms of food production, processing, distribution, and pricing. Guina et al., (2021) highlighted the extent at which COVID-19 pandemic impacted negatively both rural and urban households in terms of food security (Alemu, 2015). It is expected that agricultural-based households are likely to support their families due to their direct production of food. These activities would include access to tools and equipment crucial for tilling the land. The negative impact of the COVID-19 pandemic on food production has therefore increased the likelihood of food insecurity in rural households. On the other hand, urban households are subjected to other forms of uncertainties based on international traded commodities and exposed to external that impacts their food security status. The pandemic has caused global disruptions that broke food supply chains (Guina et al., 2021) and currently hold suburban food security on a precarious balance.

Additionally, Guina et al. (2021) show that the pandemic has destabilized the functioning of markets and hence created imbalance between demand and supply of food. The general household access to markets has been disrupted and the effects of these has been felt due to limited movement and closures of borders with neighbouring countries. This disruption affected the logistical distribution of food and increased the input costs of getting the food to the market Studies (Guina et al., 2021; Payne, 2011) displayed that utility costs, and infrastructure costs has risen considerable in recent years resulting in rise in food prices. The COVID-19 pandemic has also contributed to a surge in food prices, widened the unequal access to food and exposed the poorer population to food insecurity (FAO, 2008; Heady \& Fan, 2008).

Countries in Africa have been exposed to heightened increase in prices based on their heavy reliance on international imports (Sah \& Stiglitz, 1987). Although they are members to the World Trade Organisations, various trade instruments are not available at their disposal to protect them for excessive price increase (Barrett, 2010). Price increases exert a negative 
influence on the food security status of households when households are net food buyers and most households across the globe fall under this category. The high level of poverty in Africa status makes the continent vulnerable to these external shocks, especially those that have a direct bearing on food production (FAO, 2021). In other words, those dependent on agricultural wage suffer when price increase as their income is not adjusted for food inflation.

Another consistent theme identified by scholars that correlates positively to food security is related to demographical variables (Bonuedi et al., 2020; Kidane et al., 2005). The identified variables include the education, income and age of the household head, which are all considered crucial in ensuring the attainment of food secure status for household (Bartfeld \& Dunifon, 2006). Studies highlight that, educated breadwinners tend to be food secure (Abebaw \& Ayalneh, 2007; Grober, 2015). Conversely, female-headed households and those a with relatively higher dependency ratio (more mouths to feed), tend to experience serious food access challenges (Alemu, 2015; Bonuedi et al., 2020). Lastly, the likelihoods of being food-insecure are lower in households in wealthy neighbourhoods (higher income earners) as opposed in households low-income areas (Alemu, 2015; Kilmer and Gladwin, 2005; Muzindutsi, 2018).

\subsection{Food security in South Africa and the Empirical evidence}

Survey instruments have been used to investigate food security levels in South Africa during the post-apartheid era (Dube, 2013). Studies have employed various approaches, with some studies utilizing a mixture of qualitative approaches with quantitative and experimental methods, while others some studies have used only a one of these approaches (Bartfeld \& Dunifon, 2006; Dunga, 2018; FAO, 2008; Grobler, 2015; Hendriks, 2005; Labadorios et al.,2009; Maia et al., 2019). National representative studies continue to be carried out in the country to assess food security. Examples include the National Food Consumption Survey (NFCS) which measures food security directly, and the Labour Force and the Community Surveys undertaken by Statistic South Africa (StatSA) which provide an indirect proxy for food security at the national level (StatsSA, 2012). Other surveys measuring food insecurity indirectly include Income and Expenditure Survey (IES) and the General Household Survey (GHS). The Demographic and Health Survey (DHS) conducted by the Department of Health collects, analyses, and disseminates accurate and representative data on population, health, HIV, and nutrition in South Africa. Additionally, the data on nutrition serves as a proxy for food security based on nutritional status (Labadorios et al., 2009). These South African surveys provide findings on the level of food security in South Africa; however, some of them have limitations. Hart (2009) for instance, argues that the IES has the following shortcomings: (i) it is not designed to provide information on the quantity and quality of food purchased; (ii) it does not reflect a clear distribution pattern of food within the household; and (iii) it does not reveal the socio-economic status of a household as it does not explore the existence of networks within the community and family that may share resources. The IES indicators can be used to measure the food insecurity at the community level (Rose \& Charlton, 2002).

The NFCS has been carried out in 1999 and 2005 and it was commissioned by the Department of Health. Unlike the 1999 NFCS of which the main target group was children between the age of 1 and 9 years, the 2005 NFCS also targeted women of child-bearing age between 16 and 35 years. This survey aims to determine the food consumption pattern, usual nutrient intake, factors affecting their food consumption, prevalence of hunger, and anthropometric measurements of the target group. This data can be used to assess the food security situation of an area (Labadorios et al., 2009). The NFCS is a questionnaire-based 
measure for hunger and food security which is derived from the Community Childhood Hunger Identification Project (CCHIP)-a validated index which focuses on food insufficiency due to constrained resources. Hart (2009) criticizes this survey on the grounds that it is conducted infrequently, i.e., every five years and that the sample size is too small to arrive at such a generalized conclusion at the municipal and district level. According to the 1999 NFCS, 50 percent of South African households experienced hunger and 25percent were food insecure whilst the NFCS of 2005 revealed that 20 percent of South African households are food insecure and 50 percent of households experiencing hunger. Labadorios and Nell (2000) find that 23 percent of the country was food insecure in 1999 with the most affected being in the rural areas. This finding buttresses the statistics provided by the 1999 NFCS.

The GHS has been conducted on an annual basis by Stat SA since 2002. The survey is designed to measure the different aspects of living conditions of households in South Africa. The GHS therefore is a tool that shows households are experiencing hunger and details characteristics and geographical locations of these households. There are six broad categories included the survey, which include, agriculture, food security, health and social development, education, access by households to services, and housing (Stats SA, 2012). Hart (2009) argues that the GHS is useful and reliable in the assessment of food security because it poses subjective questions within its questionnaire that seek out self-reported experiences or perceptions of hunger for household members in the last 12 months. However, it is limited by the lack of information on the quality and quantity of the household feed and household food consumption pattern. The 2007 GHS, which also used a hunger scale, shows that 12.2 percent of children and 10.6 percent of adults experienced hunger which decreased from 20 percent children and 25 percent adults in 2002 (Jacobs, 2009).

Dietary diversity has been used to assess food security in South Africa. Two studies have been carried out in South Africa relying on the national representative samples. Labadarios et al. (2011) measure food security using dietary diversity and found it to accurately capture the food security status. Steyn et al. (2005) conduct a secondary data analysis using data from the 1999 NFCS and assess whether dietary diversity score/food variety score is an indicator for nutrient adequacy. In addition to the aforementioned studies, meta-analysis (Behzadifar et al, 2016) and review studies have been done to assess food security status in South Africa. Aliber (2009) conducts a review study that looked at food security in the country using secondary data from IES and GHS. This provides comprehensive insights into food security trends in South Africa.

In a recent study by Maia et al. (2019), the socio-economic determinants of Food insecurity were analysed with a logistic regression to ascertain the effect socio-demographic factors (gender, education, occupation, household size and structure and household income perception) on food security. A strong association between food security status and variables such as gender, education and household size was found. A recent South African study by Dunga (2018) analysed data obtained from the South African general household survey conducted by Statistics South Africa, in 2017. This study results show that household size, the gender of head of household, housing insecurity status age of head of household and income were significant determinants of morbidity rate at the household level. The present study will look at the determinants included in recent studies but will also include the location as well as the distance from the food market as variable, to analyse the access to food and the measurement of food insecurity. 
Defining the level of food insecurity in South Africa is a difficult task, as shown in the numerous surveys and data sets available at the national level which include. These surveys measure different aspects and dimensions of food security and therefore come to varying conclusions on the level of food insecurity in the country. South Africa is an upper middleincome country with a modern industrial and financial sector with a per capita GDP estimated to be US\$11911 in 2020, according to the World Bank. It is regarded as a food secure country due to its high agricultural production and the availability of an estimated $3000 \mathrm{kcal} / \mathrm{capita} / \mathrm{day}$ at national level, which is enough food for the whole population (FAOSTAT, 2021), and is higher than the average dietary energy requirement of $2400 \mathrm{kcal} /$ person/day. According to the FAO (2012), the export value index of the country has been increasing in the past 10 years. This indicates that at the national level, there is enough food and the ability to import more if need arises. Despite the availability of food, the country is still plagued with poverty, unemployment and food insecurity. This can be attributed to the high level of inequality in the country and the poor distribution of recourses and food. Thus, the high level of national food security based on the food availability cannot explain the level of insecurity observed at household level. This emphasises the need to evaluate the level of food security in lowincome areas known as townships.

\section{METHODOLOGY \\ 3.1 Empirical model}

Following Alemu (2015), this study develops an empirical model to estimate the effect of the household size, income of household head, gender of household head, location of the household and distance from food markets on food security in three townships in the Gauteng Province of South Africa. The assumptions of the model are that food is a necessity, households are rational in food consumption, households are food secured, all things being equal, and there is availability of equal information in food markets. The model is expressed as:

$$
\operatorname{Pr}_{i}=E\left(F_{i}=1 / D_{i}\right)=\Pi_{0}+\Pi_{i} D_{i}+\xi_{i}
$$

Where $\operatorname{Pr}_{i}$ is the probability that a household is food secure; $F_{i}$ denotes food security at each household level and $\mathrm{D}_{\mathrm{i}}$ is the vector comprising of household size $\left(\mathrm{HH}_{\mathrm{i}}\right)$, income of household head $\left(\mathrm{Inc}_{\mathrm{i}}\right)$, gender of household head $\left(\mathrm{GHH}_{\mathrm{i}}\right)$, location of the household $\left(\mathrm{Loc}_{\mathrm{i}}\right)$, and distance from food markets $\left(\mathrm{Fdm}_{\mathrm{i}}\right)$.

This study employs the binary logistic regression estimation approach to analyse the effect of demographic factors on food security. The suitability of this approach is justified by the categorical response nature of the dependent variable-food security. Let us consider the following representation of household food security of from Equation (1), the exponential function of the binary probability model of food security can be stated as:

$$
\operatorname{Pr}_{i}=E\left(F_{i}=1 / D_{i}\right)=\frac{1}{e^{\Pi_{0}+\Pi_{1} D_{i}+\xi_{i}}}
$$

Assuming $Z_{i}=\Pi_{0}+\Pi_{i} D_{i}+\xi_{i}$. Thus,

$$
\operatorname{Pr}_{i}=\frac{1}{1+e^{-Z_{i}}}=\frac{e^{Z_{i}}}{1+e^{Z_{i}}}
$$

Equation 3 represents the cumulative logistic distribution function, where $P r_{i}$ ranges from 0 and 1 and $Z_{i}$ ranges from $-\infty$ to $+\infty$. If $P r_{i}$ is the probability of a household being food secure, then 
$\left(1-P r_{i}\right)$ is the probability of a household being food insecure. This is mathematically expressed as:

$$
\begin{aligned}
& \left(1-P_{r i}\right)=1-\frac{e^{Z_{i}}}{1+e^{Z_{i}}} \\
& 1-P_{r i}=\frac{1}{1+e^{Z_{i}}}
\end{aligned}
$$

The odd ratio of a household being food secure to being otherwise is:

$$
\begin{aligned}
& \frac{P_{r i}}{1-P_{r i}}=\frac{e^{Z_{i}}}{1+e^{Z_{i}}} / \frac{1}{1+e^{Z_{i}}} \\
& \frac{P_{r i}}{1-P_{r i}}=e^{Z_{i}}
\end{aligned}
$$

Therefore, the estimated reduced form equation is follows:

$$
L_{i}=\eta_{0}+\eta_{1} H H_{i}+\eta_{2} \operatorname{Inc}_{i}+\eta_{3} G H H_{i}+\eta_{4} L_{o c}+\eta_{5} F d m_{i}+v_{i}
$$

Equation (8) is the binary logistic regression model estimated with the maximum likelihood (ML).

\subsection{Sampling and data collection}

The data used for this study is gathered from three townships (Atteridgeville, Soshanguve and Tembisa) in the Gauteng province of South Africa. In the geographical demarcation of South Africa, Atteridgeville and Soshanguve are in Tshwane municipality while Tembisa is in Ekurhuleni municipality. Thus, elicited information from the participants is diverse in nature since these three locations: Atteridgeville (16,456 households), Soshanguve (106,057 households) and Tembisa (166,340 households) comprises of a total of 288,853 households (StatSA, 2016).

The sample size of a large population based on survey mainly depends on three factors namely, prevalence of selected variables, desired confidence level, and the accepted level of margin of errors (IFAD, 2012). The minimum size of the sample for this study is calculated as 384 based on Cochrane's sample size formula, which is commonly used in survey research (Bartlett et al., 2001). Our sample, therefore, consists of 900 households randomly selected from the three townships (300 from each township). We used systematic random sampling with sampling interval of three, i.e., every $5^{\text {th }}$ household from the residential blocks in each township is selected. However, from the survey, only data from 827 households are retained for analysis following the conduct of rigorous coherence tests.

\subsection{Research instrument and measurement of variables}

Household Security will be measured by using the Household Food Insecurity Access Scale used by the USAID. In this scale the levels of food insecurity are categorised from severe, moderate and mild food insecurity, and measured from a value of 0 to 27, where 0 indicates complete food security. Household food security is captured by daily food consumption of at least quality three square meal. A household is food secured if they at least consumed three 
quality square meals daily, but it is food insecure if the daily consumption is less than three quality square meals. If a household is food secured, it is assigned a probability of 1, otherwise the probability is 0 . The independent variables are shown in Table 1 below.

Table 1. Description of independent Variables in Model

\begin{tabular}{|l|l|l|}
\hline Independent Variables & Description & Abbreviation in Model \\
\hline Gender & Male =1; Female=0 & GHH \\
\hline Household Size & $\begin{array}{l}\text { Total number of individuals per } \\
\text { household. }\end{array}$ & HH \\
\hline Income of Household & Total Monthly Income & Inc \\
\hline Location of Household & $\begin{array}{l}\text { Household consisting of more } \\
\text { than one individual }\end{array}$ & Loc \\
\hline Distance from Foodmarket & $\begin{array}{l}\text { Distance from market in } \\
\text { kilometres }\end{array}$ & Fdm \\
\hline
\end{tabular}

Source: Authors' compilation (2020)

\section{EMPIRICAL RESULTS AND DISCUSSION}

\subsection{Descriptive statistics}

An analysis of the food security status of households in the three townships, in Table 2, revealed that 37 percent of households in Atteridgeville are severely food insecure, 38 percent of households in Soshanguve are severely food insecure, and 18 percent of households in Tembisa are food insecure. These results showed that severe food insecurity is high in all three townships, therefore indicating a higher degree of severity than the national figures.

Table 2. Food Security Status of the three townships

\begin{tabular}{|l|c|c|c|}
\hline Food Security & Atteridgeville & Soshanguve & Tembisa \\
\hline Food Secure & $56 \%$ & $39 \%$ & $63 \%$ \\
\hline Mild Food Insecure & $3 \%$ & $9 \%$ & $9 \%$ \\
\hline Moderate Food & $5 \%$ & $13 \%$ & $11 \%$ \\
\hline Severe Food & $37 \%$ & $38 \%$ & $18 \%$ \\
\hline
\end{tabular}

Source: Authors' estimations (2020)

In Table 3 a descriptive analysis is given of the variables that will be used in the model. The HFIAS average scores are provided for each of the independent variable. Table 3 shows that 340 households in the sample are headed by males, and 487 households are headed by females. The food insecurity is more prevalent in female households with an average HFIAS score of 8.07, compared to male headed households with an average HFIAS Score of 9.10. The food insecurity is also more prevalent in households with a head of household younger than 40, with an average HFIAS Score of 6.13, and older than 65 head of households age, with an average HFIAS Score of 6.65. It is evident from the descriptive statistics that larger households have better food security than smaller household size; this could be attributed to more income earners in the household.

Table 3. Descriptive Analysis of determinants of food security

\begin{tabular}{|l|l|l|l|l|}
\hline Variables & & Sample Size & Average HFIAS & Std Dev. \\
\hline \multirow{3}{*}{ Gender } & Male & 340 & 8.07 & 8.85 \\
\cline { 2 - 5 } & Female & 487 & 9.10 & 9.02 \\
\cline { 2 - 5 } & Total & 827 & 8.68 & 8.96 \\
\hline
\end{tabular}




\begin{tabular}{|c|c|c|c|c|}
\hline Variables & & Sample Size & Average HFIAS & Std Dev. \\
\hline \multirow[t]{5}{*}{ Age } & $<40$ & 330 & 6.13 & 6.91 \\
\hline & $41-50$ & 209 & 6.68 & 7.05 \\
\hline & $51-60$ & 124 & 7.15 & 7.26 \\
\hline & $61-64$ & 36 & 8.42 & 8.34 \\
\hline & $65+$ & 128 & 6.65 & 7.60 \\
\hline \multirow{4}{*}{$\begin{array}{l}\text { Household } \\
\text { Size }\end{array}$} & 1 & 93 & 5.76 & 7.28 \\
\hline & $2-4$ & 416 & 6.31 & 6.99 \\
\hline & $5-7$ & 227 & 7.05 & 7.25 \\
\hline & $8+$ & 91 & 7.69 & 7.64 \\
\hline \multirow[t]{6}{*}{ Marital Status } & Never Married & 27 & 6.89 & 5.39 \\
\hline & Married & 338 & 5.01 & 6.71 \\
\hline & Divorced & 405 & 7.95 & 7.60 \\
\hline & Separated & 38 & 7.63 & 5.94 \\
\hline & Not Married & 5 & 2.00 & 2.92 \\
\hline & Widow/Widower & 14 & 4.57 & 3.32 \\
\hline
\end{tabular}

Source: Authors' estimation (2020)

\subsection{Analysis of determinants of food security status}

This study relies on the binary logistic regression estimation approach to show the probability effect of the household size, income of household head, gender of household head, location of the household and distance from food markets on food security in three selected townships in the Gauteng province of South Africa. The binary logistic regression estimates are reported in Table 4. The Nagelkerke $R^{2}$ is employed to evaluate the ratio of variations in food security in the Gauteng Province as a result of household size, income of household head, gender of household head, location of the household and distance from food markets. The $\mathrm{R}^{2}$ is 0.739 and this implies that 73.9 percent variations in food security level in Gauteng townships is caused by household size, income of household head, gender of household head, location of the household and distance of food markets while the remaining 26.1 percent is due to stochastic term which accounts for factors not observed in the model. The joint significance of the explanatory variables (household size, income of household head, gender of household head, location of the household and distance of food markets) is evaluated by chi-square $\left(\chi^{2}\right)$. The $\chi^{2}$ is 21.775 with p-value of 0.001 , which implies that the model is statistically significant at the 1 percent significance level. This suggests that food security in the selected Gauteng townships is jointly determined by household size, income of household head, gender of household head, location of the household and distance from food markets.

From the binary logistic regression estimates, it can be observed that the coefficient of household size $(\mathrm{HH})$ is negative and statistically significant. This finding indicates that there is decrease in the probability of achieving food security as household increase in size. This finding is consistent with Aidoo et al. (2013), who also found that larger households in Sekyere-Afram plain districts of Ghana are food insecure. The odds ratio favouring food security reduces by 0.476 when one person is added to each household. Increases in household size results in food demand that is difficult to meet by available food supplies, consequently increasing the vulnerability of households to food insecurity (Aidoo et al., 2013). The coefficient of income of household head (Inc) is positive and statistically significant and this suggests that there is an increase in the probability of food security when the income of the household head rises. This aligns with the finding of Iram and Butt (2004) for Pakistan drawn from a survey of 16,305 households based on the Pakistan Integrated Household Survey. A rise in the income of household head increases the odds ratio in support of achieving food security by 0.473 . 
Household heads with higher income are more likely to be able to afford food at prevailing prices compared to those with low income. Frayne and McCordic (2015) argue that food insecurity is associated with erratic or no access to income.

Table 4. Binary logistic regression estimates

\begin{tabular}{|c|c|c|c|c|}
\hline Variable & Coefficient & Wald ratio & P-value & Odds ratio \\
\hline Intercept & 4.438 & 43.298 & 0.000 & 84.590 \\
\hline $\mathrm{HH}$ & $-0.742 * * *$ & 11.385 & 0.001 & 0.476 \\
\hline Inc & $0.828 * * *$ & 9.910 & 0.002 & 0.437 \\
\hline$\overline{\mathrm{GHH}}$ & $-0.859 * * *$ & 9.789 & 0.002 & 0.424 \\
\hline Loc & $-0.310^{*}$ & 2.813 & 0.094 & 0.734 \\
\hline Fdm & -0.261 & 1.909 & 0.167 & 0.770 \\
\hline Nagelkerke $\mathrm{R}^{2}$ & 0.739 & & & \\
\hline$\chi^{2}$ & $\begin{array}{l}21.775(0.001) \\
* * *\end{array}$ & & & \\
\hline Sample size $(n)$ & 827 & & & \\
\hline
\end{tabular}

The gender of household head (GHH) has a negative and statistically significant coefficient, and this finding indicates that a change in the gender of the household head may increase the chance of the household to experience food insecurity. The odds ratio in favour of food security declines by 0.424 when the gender of the household head changes from female to male. Female-headed households tends to allocate a higher proportion of their income to food compared to male-headed households (Kennedy \& Peters, 1992). Moreover, the coefficient of location of the household (Loc) is negative and statistically significant. This finding suggests that the probability of food security diminishes when there is a change in location of the household. The odds ratio, indicating the potential of a household being food secure, falls by 0.734 when the household changes location. The coefficient of distance from food markets (Fdm) is negative but not statistically significant, indicating that the probability of a household being food secure is not affected by how far or close the household is to the food markets.

\section{CONCLUSIONS AND RECOMMENDATIONS}

Ensuring food security is a major preoccupation for virtually all countries. Identifying the factors responsible for food security is paramount for understanding how food insecurity can be averted. Although literature on food security is abound, the discourse on food security still remains a topical issue in African countries. Focusing on South Africa, this study examines the effects of household size, income of household head, gender of household head, location of the household and distance of food markets on food security at household level. Such a study is relevant for a country like South Africa, where various aspects of urbanization have contributed to household food insecurity among the poor who live primarily in townships. The idea that food insecurity is driven by non-availability of food supply could be spurious in urban contexts especially among the poor. Utilizing the binary logistic model estimation approach on household level data from the three townships in the Gauteng province of South Africa, the empirical results showed that the income of the head of the household has a positively and significant effect on food security while the size of the household, gender of household head, and location of the household, exert a negative and significant contributory effect. Similarly, it discovers that distance from food markets has no effect on food security. These results suggest 
that household head's income ensures food security while household size, gender of household head, and location of the household are responsible for food insecurity. With respect to distance from food markets, it does not play a role in determining food security levels. It is also worth stating that this study shows that a change of gender of household head from female to male considerably reduces the household food security level of the household. The implication of this is that female have greater ability to ensure household food security. Studies have linked this to greater ability of women to access many income sources relative to men hence they are better at planning household food consumption. Thus, in addition to providing sufficient food, policymakers should focus on improving the planning and management of food consumption in urban low-income households. Additionally, our findings reveal the need to enhance the food supply chain to stabilize the demand side of food security. Such enhancement of food supply is essential during the COVID-19 pandemic, which has amplified food insecurity in most African countries. Overall, our findings reemphasize the need for developing strategies to deal with growing concerns of food insecurity in the low-income urban area of South Africa known as townships.

\section{REFERENCES}

Abebaw, S. \& Ayalneh, B. (2007). Dimensions of food insecurity and livelihood strategies among rural households in Dire Dawa, Eastern Ethiopia. Tropical Science, 47(2), 73-80.

Aidoo, R., Mensah, J. O., \& Tuffour, T. (2013). Determinants of household food security in SekyereAfram plains district of Ghana. Proceedings of $1^{\text {st }}$ Annual International Interdisciplinary Conference (pp. 514-521).

Alemu, Z. G. (2015). Developing a food security map for South Africa. Working Paper No.220, Africa Development Bank Group, Abidjan, Côte d'Ivoire.

Aliber, M. (2009). Exploring statistics South Africa's national household surveys as sources of information about household-level food security. Agrekon, 48(4), 384-409.

Bartlett, J., Kotrlik, J. \& Higgins, C. (2001). Organizational research: Determining sample size in survey research. Information Technology, Learning and Performance Journal, 19(1), 43-50.

Bartfeld, J., \& Dunifon, R. (2006). State-level predictors of food insecurity among households with Children. Journal of Policy Analysis and Management, 25(4), 921-942.

Barrett, C. B. (2010). Measuring food insecurity. Science, 327(5967), 825-828.

Battersby, J. (2011). The state of urban food insecurity in Cape Town. Urban Food Security Series No. 11, Queen's University and AFSUN, Kingston and Cape Town.

Behzadifar, M., Behzadifar, M., Abdi, S., Malekzadeh, R., Salmani, M.A., Ghoreishinia, G., Falahi, E., Mirzaei, M., Biranvand, N.S. \& Sayehmiri, K., (2016). Prevalence of food insecurity in Iran: a systematic review and meta-analysis. Archives of Iranian medicine, 19(4), 288-294.

Boadi, K., Kuitunen, M., Raheem, K., \& Hanninen, K. (2005). Urbanisation without development: environmental and health implications in African cities. Environment, Development and Sustainability, 7(4), 465-500.

Bonuedi, I., Kamasa, K. \& Opoku. E. E. O. (2020). Enabling trade across borders and food security in Africa. Food Security, 12, 1121-1140.

Charlton, K., Rose, D. (2002). Prevalence of household food poverty in South Africa: Results from a large, nationally representative survey. Public Health Nutrition 5(3):383-9, DOI:10.1079/PHNPHN2001320

De Janvry, A., \& Subbarao, K. (1984). Agricultural price policy and income distribution in India. Economic and Political Weekly, 19, 166-178.

Devereux, S., \& Maxwell, S. (2001). Food security in sub-Saharan Africa. ITDG Publishing.

Dreze, J., \& Sen, A. (1989). Hunger and public action. Democracy in India, 311-325.

Dube, E. M. (2013). Food security in South Africa: A comprehensive review of the past two decades. Universiteit Gent, Belgium.

Dunga, S. H. (2018). The Relationship between Health Outcomes and Household Socio-Economics Characteristics. Journal of Economics and Behavioral Studies, 10(6A), 89-96. 
FAO (1996). Socio-political and economic environment for food security. World Food Summit, Vol. 1, Sec. 1.4., Food and Agriculture Organization, Rome. http://www.fao.org/3/W3613E/ W3613E00.htm. Date of Access [19 May 2021]

FAO (2006). Food Security Policy Brief, June 2006.http://www.fao.org/fileadmin/templates/faoitaly/documents/pdf/pdf_Food_Security_Coce pt_Note.pdf. Date of Access [19 May 2021]

FAO (2008). The state of food insecurity in the world. Food and Agriculture Organization, Rome.

FAO (2012). The state of food insecurity in the world: 2012 key messages. Food and Agriculture Organization, Rome.

FAO (2021). FAOSTAT DATABASE. http://www.fao.org/faostat/en/\#home. Date of access [19 May 2021]

Frayne, B., \& Mc Cordic, C. (2015). Planning for food secure cities: Measuring the influence of infrastructure and income on household food security in Southern African cities. Geoforum, 65, $1-11$.

Grobler, W. C. J. (2015). Urban food insecurity: A case for conditional cash grants. Inaugural speech on 12 November 2015.

Guina, J., Ferrão, J., Bell, V., \& Fernandes, T. (2021). The impact of COVID-19 in sub-Saharan Africa food security and human development. European Journal of Agriculture and Food Sciences, 3(2), 34-40.

Hart, T. G. (2009). Exploring definitions of food insecurity and vulnerability: time to refocus assessments. Agrekon, 48(4), 362-383.

Heady, D. \& Fan, S., (2008). Anatomy of a crisis: the causes and consequences of surging food prices. Agricultural Economics,39, 375-91.

Hendriks, S. L. (2005). The challenges facing empirical estimation of household food (in) security in South Africa. Development Southern Africa, 22(1), 103-123.

Idachaba, F. (2004). Food security in Nigeria: challenges under democratic dispensation. Paper presented at ARMTI Lecture, Ilorin on 24 March 2004.

International Fund for Agricultural Development (IFAD) (2012). Methodologies for Impact Assessments for IFAD9. EB 2012/107/INF.7. International Fund for Agricultural Development, Rome.

IPC (Integrated Food Security Phase Classification). 2021. South Africa: Acute Food Insecurity Analysis, September 2020- March 2021. www.ipcinfo.org/ipc-country-analusis. Date of Access [19 May 2021]

Iram, U., \& Butt, M. S. (2004). Determinants of household food security: An empirical analysis for Pakistan. International Journal of Social Economics, 31(8), 753-766.

Jacobs, P. (2009). Identifying a target for food security in South Africa, Unpublished report, Center for Poverty, Employment and Growth, Human Science Research Council, Pretoria.

Kennedy, E., \& Peters, P. (1992). Household food security and child nutrition: The interaction of income and gender of household head. World Development, 20(8), 1077-1085.

Kidane, H., Alemu, Z. G., \& Khundhlande, G. (2005). Causes of household food Insecurity in Koredegaga Peasant Association, Oromiya zone, Ethiopia. Agrekon,44(4), 543-560.

Labadarios D, Steyn NP, Nel JH: How diverse is the diet of adult South Africans? Nutrition Journal. 2011, 10: 33-10.1186/1475-2891-10-33. Date of Access [19 May 2021] [http://www.nutritionj.com/content/10/1/33]

Labadarios, D. and Nel, H.H. (2000). Chapter 4: Anthropometric Status. In: Labadarios, D. (ed.). The National Food Consumption Survey (NFCS): Children aged 1-9 years, South Africa, 1999. The National Food Consumption Survey (NFCS), Stellenbosch.

Maia, I., Monjardino, T., Lucas, R. (2019) Household food insecurity and socio-demographic determinants in young adults: findings from a Portuguese population-based sample. Int J Public Health 64, 887-895 (2019). https://doi.org/10.1007/s00038-019-01243-y

Maxwell, S. (1996). Food security: a post-modern perspective. Food Policy, 21(2), 155-170.

Memon J.A., El Bilali H. (2019) Rural Infrastructure and Food Security. In: Leal Filho W., Azul A., Brandli L., Özuyar P., Wall T. (eds) Zero Hunger. Encyclopedia of the UN Sustainable Development Goals. Springer, Cham. https://doi.org/10.1007/978-3-319-69626-3_44-1 
Munir, J., Esteban, T.Z. 2011. Pass -through of international food prices to domestic inflation during and after the great recession: evidence from a set of Latin American Economies. Journal Desarrollo Y Sociedad, Soc. No.67. Bogota, Jan/June 2011.

Muzindutsi, P. F. (2018).A comparative analysis of income-and asset-based poverty measures of households in a Township in South Africa.International Journal of Economics and Finance Studies, 10(1), 184-202.

National Department of Agriculture (NDA) (2002). The Integrated Food Security Strategy for South Africa, Pretoria.

O'Laughlin, B. (1999). In defence of the household: Marx, gender and the utilitarian impasse. In: ISS Working Paper Series/General Series, Vol. 289, Erasmus University, Rotterdam.

Olayemi, J. K. (1998). Food security in Nigeria. Development Policy Centre, Ibadan

Omonona, B., Agoi, T., \& Adetokunbo, G. (2007). An analysis of food security situation among Nigerian urban households: evidence from Lagos State, Nigeria: Journal of Central European Agriculture, 8(3), 397-407

Oriola E. O. (2009) A framework for food security and poverty reduction in Nigeria. European Journal of Social Sciences, 8(1),

Payne, T. (2011). Food prices pummel the poor. Mail and Guardian, 9 December 2011.

Ravallion, M. (2002). On the urbanization of poverty, Journal of Development Economics,68(2), 435442.

Sah, R. K., \& Stiglitz, J. E. (1987). Price scissors and the structure of economy. Quarterly Journal of Economics, 102, 109-134.

Sanni, L. O. (2000) Agricultural development without post-harvest system: Any hope for success? University of Agriculture, Abeokuta Alumni Association Lecture Series No. 2.

Sen, A. (1981). Poverty and famines: an essay on entitlement and deprivation. Oxford University Press, USA.

Shiferaw T. F., Kilmer, R. L., \& Gladwin, C. H. (2005) Determinants of food security in Southern Ethiopia at the household level. Agricultural Economics,33(3), 351-363.

Spiegel, A. D. (1995). Migration, urbanisation and domestic fluidity: reviewing some South African examples. African Anthropology, 2, 90-113.

Statistical Report on Social Grants. (2019). http://www.sassa.gov.za (Date of access: 10 Feb 2020).

StatsSA (2012). Social profile of South Africa, 2002-2012. Government Printer, Pretoria.

StatsSA (2016). Population Statistics. http: www.Statssa.gov. Date of Access [19 May 2021]

Steyn, N., Nel, J., Nantel, G., Kennedy, G., \& Labaradorios, D. (2005). Food variety and dietary diversity scores in children: are they good indicators of dietary adequacy? Public Health Nutrition, 9(5), 644-650.

South African Social Security Agency (SASSA). SASSA Annual Report 2014/15. http://www.sassa.gov.za.

United Nations. (1975). Report of the world food conference, Rome 5-16 November 1974. New York

U.S. Department of Agriculture (USDA) (2006). Food security in the United States: definitions of hunger and food security. Economic Research Service.

U.S. Department of Agriculture (USDA) (2009). Access to affordable and nutritious food: measuring and understanding food deserts and their consequences. Report to Congress, June 2009. Available online: http://www.ers.usda.gov/Publications/AP/AP036/

Young, E. M. (2004). Globalization and food security: novel questions in a novel context? Progress in Development Studies, 4(1), 1-21. 